\title{
Could the Giant Buddha Statues of Bamiyan Be Considered as a Case of "Exceptional Circumstances" for Reconstruction?
}

\author{
Junko Okahashi
}

\begin{abstract}
According to the World Heritage Operational Guidelines, reconstruction of cultural heritage is only justifiable in "exceptional circumstances". In an attempt to understand the destroyed Giant Buddha statues of Bamiyan as such, this paper revisits discussions on reconstruction by reviewing relevant international doctrines. It argues that this case meets the definition of "exceptional cases" in the Riga Charter, where reconstruction of artefacts recovers significance of a place, in response to tragic sense of loss caused through man-made disasters. However, the issue of authenticity is yet to be discussed. How does the notion of authenticity apply to destructed heritage? This connects to the question of who wishes to remember what and how and what is the value of reconstruction itself for the concerned community. Clarification on the process of consensus building is key to justification of reconstruction. As stated in the Warsaw Recommendation, reconstruction should enable people to connect to their heritage, identity and history. If the Bamiyan statues resurrect in the future, it would be for restitution of historic memory. Significance of reconstruction lies in the rehabilitation of social livelihood and self-esteem among the directly affected. When reconstruction brings such situation, it may be accepted as a means of future management.
\end{abstract}

Keywords Reconstruction · Authenticity · Exceptional circumstances · International doctrines $\cdot$ Historic memory $\cdot$ Spirit of place $\cdot$ Identity $\cdot$ Restitution Significance

Published jointly by the United Nations Educational, Scientific and Cultural Organization (UNESCO), 7, place de Fontenoy, 75007 Paris, France, the UNESCO Office in Kabul, ICON Compound, Supreme Road, Off Jalalabad Road, PD 9, Kabul, Afghanistan, and Springer Nature Switzerland AG, Gewerbestrasse 1, 6330 Cham, Switzerland.

J. Okahashi $(\bowtie)$

School of International Studies, University of the Sacred Heart, Tokyo, Japan

e-mail: okahashi@u-sacred-heart.ac.jp 


\section{Introduction}

The present paper argues what should be the conditions for a place or an element of cultural heritage to be considered as an "exceptional" case, so as its reconstruction could be acceptable.

When discussion is held around reconstruction of cultural heritage, it is to be noted that the common understanding of the language is not established. Even among the scientific community in the field of cultural heritage, definition of reconstruction varies from the very monumental, strictly differentiating reconstruction and restoration to social, urban and environmental. The intended scale of the intervention also differs from a partial addition of an existing structure to entire rebuilding of a lost built environment.

This paper, in general, offers a necessary descriptive review of literature, notably the principle international platform-setting texts, which have shaped the doctrine and attitude towards reconstruction of cultural heritage on the international level. In order to argue a possible shift in the paradigm, as it were, to place cultural heritage as future-making tool, seeing future as equally important as past and present in the life and spirit of a place, no principle could be put forward without respecting the accumulation of continued discussion on the justified or non-justified acts of reconstruction.

The arguments shall be the following. Firstly, are the Giant Buddha statues of Bamiyan considerable to be of exceptional circumstances for reconstruction? In the language of the Operational Guidelines for the Implementation of the World Heritage Convention (hereafter Operational Guidelines, 2019 version), the reconstruction of archaeological remains or historic buildings is said to be justifiable only in "exceptional circumstances". In an attempt to understand the destroyed Giant Buddha statues of Bamiyan in part as a case of "exceptional circumstances", the statement in the Riga Charter on Authenticity and Historic Reconstruction in Relationship with Cultural Heritage (2000, hereafter the Riga Charter) must be addressed, that "exceptional circumstances" are where reconstruction is indispensable for the "survival" of a place, where it can recover the place's cultural significance.

Secondly, if they are indeed of "exceptional circumstances", do we then have the conditions ready, i.e. complete documentation, processes and linkages with continued living spirit, etc., so as to evaluate that they would be "authentic" even after reconstruction? This point is to be reconsidered.

Thirdly, how and to what extent does the notion of authenticity itself apply in the case of destructed heritage, if we think about reconstruction in "exceptional circumstances" to be "for the future"?

Overall, the purpose of reconstruction must be revisited. In the Warsaw Recommendation on Recovery and Reconstruction of Cultural Heritage (2018, hereafter Warsaw Recommendation), there is an attempt to understand the term "reconstruction" in the World Heritage context as "a technical process for the restitution of destroyed or severely damaged physical assets and infrastructure following 
an armed conflict or a disaster" and that "it is important to stress, in this regard, that such reconstruction of physical assets must give due consideration to their associated intangible practices, beliefs and traditional knowledge which are essential for sustaining cultural values among local communities". In compliance with this understanding, should the Giant Buddha statues of Bamiyan be reconstructed, the significance would be sought in the restitution of historic memory and identity. This paper argues that the Bamiyan case could meet the definition for "exceptional cases" in the Riga Charter, because the reconstruction of artefacts might recover the cultural significance of a place, in response to tragic sense of loss caused through disasters of human origin. However, in this case, we would come to rethink the issue of authenticity and unavoidable elements of conjecture, where there might be the need to interpret the newly installed elements as an honest expression of the present towards the future. This is directly connected to the question of who wishes to remember what and how, who are the stakeholders and what is the value of reconstruction for the "concerned community".

\section{2 "Exceptional Circumstances" According to the International Doctrinal Texts}

In the world today, facing frequent issues of devastation of cultural heritage, at what times and situations could reconstruction be an appropriate method of conservation, in order to optimize presentation and enhancement of cultural heritage, allowing the contemporary society to live with it? The current concerns of the present author attempts to better interpret the following article of the Operational Guidelines. Article 86 of the Operational Guidelines reads as following:

In relation to authenticity, the reconstruction of archaeological remains or historic buildings or districts is justifiable only in exceptional circumstances. Reconstruction is acceptable only on the basis of complete and detailed documentation and to no extent on conjecture.

In the Riga Charter (2000), "exceptional circumstances" are described as the following:

Circumstances where reconstruction is necessary for the survival of the place; where a 'place' is incomplete through damage or alteration; where it recovers the cultural significance of a 'place'; or in response to tragic loss through disasters where of natural or human origin.

According to this definition, reconstruction could possibly be justified as appropriate when incompleteness, which may hinder survival of a place, is widely felt after destruction and where the act of reconstruction would recover the place's cultural significance. Furthermore, it is to be noted that, even being defined to be under the above-mentioned exceptional circumstances, the Charter clarifies fundamental conditions of reconstruction that: 
- appropriate survey and historical documentation is available (including iconographic, archival or material evidence);

- existing significant historic fabric will not be damaged: and,

- (...) the need for reconstruction has been established through full and open consultations among national and local authorities and the community concerned.

Needless to say, the approach towards reconstruction seen in the text of the Riga Charter, in relation to authenticity, is aligned within paragraphs 79 to 86 of the Operational Guidelines. The provisions in the Riga Charter are also based on thorough studies of the Venice Charter as well as other ICOMOS doctrinal texts, namely, the Burra Charter (1979), the Florence Charter (1981), the Declaration of Dresden (1982), the Lausanne Charter (1990), and the Nara Document (1994). The Riga Charter hence reorganized and summarized, in a clear language, the development of thoughts against various political and social backgrounds, until 2000, on the notion of reconstruction of cultural heritage. Therefore it could be noted that covering the conditions set out in the Riga Charter would be able to respect the accumulation of preceding conventional texts.

\section{Background on the Bamiyan Buddha Statues}

Destruction of the two standing Giant Buddha statues in Bamiyan, in 2001, was far from what the local community wished for. The local people of Bamiyan lived with the statues for over a millennium, as if the standing giant statues were their friends or extended family, just as members of their community. The statues had their eyes carved off from the faces at some point in history, but in principle, the local community, long time mainly Shiites, had little issue of idolatry about the Buddha statues. They were not objects of worship any more, but were instead regarded as part of their community. The sense of loss and incompleteness without the Giant Buddha statues, for the viewpoint of the local community, affects the so-called integrity or "wholeness" of the World Heritage property of the Bamiyan Valley.

When living cultural heritage sites that exert important function on the social and economic livelihood of the concerned community are destroyed intentionally in armed conflicts or as a result of natural disasters, one may strongly support that these are "exceptional circumstances" to become candidates for reconstruction. However, when we consider what a living heritage means, clear images exist for places of religious and spiritual significance, cultural landscapes involving on-going human activities as well as dynamic environment subject to the historic urban landscape approach. In the case of the Giant Buddha statues of Bamiyan, their contemporary role may not be strong enough to be proved as living heritage; however, purpose of memory and identity restitution becomes a stronger justification for the recovery of cultural significance.

On the other hand, would the daily lives of the local community be safe and secure with any newly reconstructed figure, of which the strong symbolism became target of destruction? What decision could be acceptable for the largest number of 
stakeholders? Where can the financial means be procured, and could any international donor follow the will of the national and local stakeholders? The set of realistic issues are continuously at stake, to be centred on the clarity of decision-making process, "by whom" and "for whom" the decision can be made. In the meantime, the theory of cultural heritage reconstruction is in need of an international review of principles.

It is to be noted here that the rebuilding purpose would not be the same as when the Giant Buddha statues were first built in the sixth century AD, when religious and spiritual values were carved into the stone figures. The statues were then of religious significance and for worshipping purposes of the Buddhist monastic community which had been formulated at this crossroad of civilizations. Hence the international community should admit that any debated reconstruction of the colossal statues at Bamiyan is not about continuation of living intangible cultural practices, but much rather a choice to restitute historic memory and identity. The present author considers that authenticity may be sought in the new statue itself, while it is rather difficult to justify the continuity of spirit and context from the time of creation of the destructed original statues. Attempts to make use of the physically secured stone fragments of the statues may well be in respect of the Venice Charter. However, the Venice Charter is not necessarily relevant to all types of cultural heritage. It may indeed be an appropriate option to reuse the conserved stone pieces; nevertheless, strict anastylosis leaving patches of lacuna with recognizable modern material may not be applicable to this type of cultural heritage, originally built as figures of worship, thus in an esthetically harmonious physical form.

Who is the testimony of whom? There is the local community of Bamiyan and dedicated researchers who have eyewitnessed the before and after of the destruction of the Giant Buddha statues. However, the destructed statues, who stood there for 1.5 millennia, were also themselves testimonies of various movements from east to west and from west to east: Military invaders and destroyers passed through, from old days till very recent; pilgrims and monks travelled between China and India passing in front of the Buddha statues in search of precious sutras; lacquerware, spice, ivory and all kinds of other goods were delivered from caravanserai to caravanserai, under the eyes of the Buddha statues. The non-existence of the statues themselves means the symbolic loss of the testimony of richness in the history of interchange in Bamiyan. Thus without the statues, the place may continue to be felt as "incomplete".

What is to be remembered, in what form? The answer to this question becomes key to accept or not the Giant Buddha statues of Bamiyan as an exceptional case for reconstruction. Does Afghanistan want to remember the tragic event of destruction of the Buddha statues? Or else, does its citizens prefer to remember the millenniumlong friendship and relationship with the Buddha statues? The choice to reconstruct or not would largely depend on the will of the present day's stakeholders and on "what" they wish to remember and transmit to future generations. Currently, the two empty niches exert a tremendously large message to the world. However, this delivered message would be appropriate only when the chosen memory is about the loss, the destruction. 


\section{Discussion on Authenticity and Reconstruction from International Doctrinal Texts}

Presuming that the Giant Buddha of Bamiyan statues are indeed of "exceptional circumstances" for reconstruction, there are yet issues of having or not the complete documentation for such reconstruction, to be dealt as truthful and honest or not, the question of "authenticity", which should be reconsidered. Here, this paper shall go through a necessary descriptive review of some important international texts. No updated principle could be put forward without respecting the accumulation of texts reflecting the past discussions, in the field of cultural heritage conservation, on the acts of reconstruction.

In the International Charter for the Conservation and Restoration of Monuments and Sites (1964, hereafter the Venice Charter), its Article 9 reads as follows:

The process of restoration is a highly specialized operation. Its aim is to preserve and reveal the aesthetic and historic value of the monument and is based on respect for original material and authentic documents. It must stop at the point where conjecture begins, and in this case moreover any extra work which is indispensable must be distinct from the architectural composition and must bear a contemporary stamp. The restoration in any case must be preceded and followed by an archaeological and historical study of the monument.

In Articles 12 and 13, it instructs the principles on replacement of missing parts and additions:

Replacements of missing parts must integrate harmoniously with the whole, but at the same time must be distinguishable from the original so that restoration does not falsify the artistic or historic evidence. Additions cannot be allowed except in so far as they do not detract from the interesting parts of the building, its traditional setting, the balance of its composition and its relation with its surroundings.

The Venice Charter respects honesty in conservation decisions and attempts to ensure material integrity of the built heritage. Then, we see in Article 15 the exceptional admittance of "reconstruction":

(...) All reconstruction work should however be ruled out "a priori”. Only anastylosis, that is to say, the reassembling of existing but dismembered parts can be permitted. The material used for integration should always be recognizable and its use should be the least that will ensure the conservation of a monument and the reinstatement of its form.

The condition of reconstruction here is to use the practice of anastylosis. This also demonstrates the respect for honesty in conservation decisions, towards the material integrity of the built heritage. However, this Article 15 is where the Charter talks about archaeological excavations. There is little assumption of a situation where reconstruction of built environment may be needed for anything that continues to be used and lived in. This is clearly restrictive to certain category of heritage, using some limited variety of material. Reconstruction has been seen as paradox to what heritage conservation means, especially when the theory has focus on the "preservation" aspect. 
Then, when we read the Nara Document on Authenticity (1994, hereafter the Nara Document), which has now become a widely consulted reference upon consideration of authenticity, we realize that it does not, in fact, clearly define what authenticity itself means. However, it certainly gives guidance on the relative way of seeking authenticity and gives high consideration to the existing "diversity" in the world, towards the notion of authenticity, as well as on the categories of cultural heritage. It successfully expanded the grounds or "aspects of sources of information" on which evaluation of authenticity could be made. Reconstruction may be justified in line with some of those grounds. Article 13 of the Nara Document states as follows:

\footnotetext{
Depending on the nature of the cultural heritage, its cultural context, and its evolution through time, authenticity judgments may be linked to the worth of a great variety of sources of information. Aspects of the sources may include form and design, materials and substance, use and function, traditions and techniques, location and setting, and spirit and feeling, and other internal and external factors. (...)
}

The achievement of the Nara Document was that it could allow diverse cultures of the world, not only Japan, to be able to put forward the values of their important cultural heritage as authentic. The authenticity statement in the Nara Document became the basis of paragraphs 79-86 of the Operational Guidelines since its 2005 revised version and became influential in the World Heritage Outstanding Universal Value identification worldwide. However, the challenge within the international debates was then that the notion on authenticity, having become more relative and diversity-oriented since the Nara Document, no longer held the threshold of standardized judgement. Also, despite the applause and respect given to the achievement of the Nara Document, the notion and placement of reconstruction was not articulated in the text. The Nara Document is silent about the linkage of the two notions of authenticity and reconstruction, although it might have otherwise become the opportunity to guide some development in reconsidering the significance of reconstruction within the international standards. It was not yet high time in 1994 to come to that point. Relative expansion of the notion of authenticity was enough as a big step forward at that stage, in order to pave way for diversity and universality in the international doctrine.

Then in the Riga Charter (2000), historic reconstruction of cultural heritage is clearly defined as "evocation, interpretation, restoration or replication of a previous form". In the same text, conservation is defined as "all efforts designed to understand cultural heritage, know its history and meaning, ensure its material safeguard, and as required, its presentation, restoration and enhancement".

When we review the content of the Riga Charter, within its conciseness, it shows the result of a revisited debate on reconstruction. The Riga Charter was signed in 2000 following concerns on reconstruction and authenticity issues in some former Soviet countries, which had regained independence after the dissolution of the Cold War. This Charter became an alert, from the doctrinal point of view for the conservation of cultural heritage to the use of reinvented monuments as symbolic narratives for national identity building and restructuring of national history. One may 
argue why not, since the common motivation of concerned communities towards reconstruction tends to be the restitution of historic and cultural identity. However, the Charter reminds the public that any reconstruction is the least necessary for the conservation and presentation of a cultural heritage site.

In the Riga Charter, unlike the Nara Document, the notion of authenticity and reconstruction are related within the single text. On authenticity, it defines that:

Authenticity is a measure of the degree to which the attributes of cultural heritage (including form and design, materials and substance, use and function, traditions and techniques, location and setting, and sprit and feeling, and other factors) credibly and accurately bear witness to their significance.

One of the principal authors of the Riga Charter, who also led the work of the Nara Document, made sure that the Charter enhanced the approach of the Nara Document, even before it entered into the text of the Operational Guidelines in 2005.

Here, we should be reminded of honesty that can be proved in replications. Cesare Brandi, in his Theory of Restoration (1977), mentions that falsity does not lie within the object but within the judgement. A fake becomes a fake when it is recognized as such, and falsity is not an inherent property of the object. He underlines the importance of distinguishing between imitations (or replicas) and falsifications and that the differentiation is not based on specific differences in production methods but on the underlying intent. The former is the "production of an object that resembles or reproduces another object, either in the technique or in the style of a given historical period or a given artist, with no purpose other than to document or enjoy the object". ${ }^{1}$ The latter is "production of an object as above, but with a specific intent to mislead others as to its period, its material nature or its creator". ${ }^{2}$ According to his theory, entire or partial reconstruction or destructed built environment could be perhaps seen as "imitation". Imitation is not falsification, so it is still honest. In this case, couldn't reconstruction be accepted, if it is achieved without concealing that it is indeed a reconstruction? This may lead to another level of debate that cultural heritage could still be significant without being entirely authentic from all aspects.

However, against the argument of honesty in replications, the Riga Charter states that:

Replication of cultural heritage is in general a misrepresentation of evidence of the past, and that each architectural work should reflect the time of its own creation, in the belief that sympathetic new buildings can maintain the environmental context.

Then, isn't there a way to approve authenticity within the reconstruction act itself, if it meets the affirmative judgement on authenticity within the grounds given in the Nara Document, therefore also in the Riga Charter and the Operational Guidelines? Reconsideration on the linkage of authenticity and reconstruction is highly at stake, since there is no mention in any doctrinal texts on the specific way to evaluate

\footnotetext{
${ }^{1}$ Brandi, C. (1977). Teoria del Restauro, English Edition: Brandi, C. (2005). Theory of Restoration. translated by Rockwell, C. edited by Istituto Centrale per il Restauro. Nardini Editore. Firenze. P.87 ${ }^{2}$ ibidem
} 
authenticity in reconstructed cultural heritage. Perhaps discussions based on the "authenticity vs. conjecture" mindset are not relevant enough to the quite unique issues arising from reconstruction in "exceptional cases". When reconstruction of cultural heritage brings meaning for identity-rebuilding towards the future, as long as there is no falsification between what used to be there and what is new, honesty may be identified within the new, significant as it is, ensuring value continuity from what used to be there, thus contextual integrity, bridging the old and the new.

\section{Comparative Discussion on Reconstruction in "Exceptional Circumstances", Memory and Future Building}

As seen in the above texts, for certain, discussions on reconstruction and authenticity have been repeated. However, in our times, we are to reopen the debate, in order to identify how to consider reconstruction of destroyed or damaged cultural heritage, due to the fact that pressing international expectations towards a persuasive scientific viewpoint of cultural heritage specialists become non-negligible. What appears in the forementioned doctrinal texts as "exceptional circumstances", where reconstruction of cultural heritage might be supported, happens frequently in today's world. Armed conflict is destroying emblematic historic monuments and places of living heritage, devastating the identity and esteem of the local community and a larger public far beyond; when we see it, universal concerns and empathy are raised on the future of the place.

In this context, the present author emphasizes the conditions of intentional destruction through armed conflict as key to the argument of this paper, specifically in connection to the role of reconstruction as "future-making" as well as the forementioned need of revisiting the notions of authenticity and new elements.

A successful case of reconstruction in the recent years was at the monuments in Timbuktu (Mali), which could be read in the international news articles as well as in the press communication by UNESCO. The mausoleums of saints in Timbuktu, built since the thirteenth century, have long been places of pilgrimage for the people in the region. 16 of them are inscribed on the World Heritage List, but 14 were destroyed in 2012, under attack by armed groups, representing a tragic loss for local communities. Based on detailed documentation and material laid by skilled local craftsmen and work by the living community for the living community, this case merited an international applause, at the 39th session of the World Heritage Committee in 2015, far from being criticized because of "reconstruction". Mausoleums in Timbuktu being places of worship by the continuously living community and justification of authenticity are clearly sought in reference to some of the "aspects of information sources" mentioned in the Nara Document.

Older cases can also be named, such as the reconstructed old city of Warsaw (Poland), although the context and scale of the reconstruction varies from the case 
of Timbuktu. Those cases may become sources of reflective comparison for the ongoing international discussions on Bamiyan, concerning reconstruction of the Giant Buddha statues. The international community relates the issue to even more recent emblematic victims of armed conflict, such as places of cultural significance in Syria, Iraq or Yemen. When those cultural heritage sites exert important function on the social and economic livelihood of the concerned community, there is no question about the need of a large-scale intervention, which may be called reconstruction, in order to secure "survival" of the place.

The prominent past example of cultural heritage reconstruction is the case of the old town of Warsaw. Warsaw dates back to the Gothic period and underwent numerous transformations over the centuries, extensively rebuilt during the seventeenth and eighteenth centuries. During World War II, especially during and after the Warsaw Uprising in 1944, Warsaw was bombed by the Nazi, which reduced 85-90\% of the city's historic centre to rubbles. The decision on its post-war reconstruction was global in its scale, with a push of international politics by the Soviet Union. However, there was certainly a strong living reason by the survived local population to re-establish its housing environment, which they had already been initiating by themselves. After the Warsaw Uprising, the population of Warsaw was reduced from over 1 million to only a few thousand people living in its ruins. Then, post-war period had its pressing needs to reaccommodate a recovering population.

Meticulous collecting and reuse of the remnants of the historic Warsaw ended up, after many years, in recreating the entire historic fabric of an old city. This method became the basis of a principle, which was then applied to reconstructing the historic districts of Gdańsk, Wrocław, and further on became influential to other European cities in recovering their urban heritage. This was one of the reasons why the reconstructed Historic Centre of Warsaw was listed on the World Heritage List in 1980.

When we study the World Heritage nomination dossier of the entirely reconstructed Historic Centre of Warsaw, it can be understood that the Polish authorities did not intend to declare the authenticity in the destructed layers of history, but declared contemporary sources of genuineness that existed within the resurrected old town, by and large in the style of the eighteenth century, which was the exertion of the work of $1949-1963^{3}$ reconstruction itself. It was set forth as an unprecedented example of reconstruction on an urban scale. The reconstruction work from scratch was implemented by prominent and ardent Polish architects, urban planners and conservators, based on the compiled pre-war drawings and photographs, ${ }^{4}$ as well as iconographic sources and documents from throughout the history of the city, including its cityscapes by the eighteenth-century Venetian painter Bernardo Bellotto. The

\footnotetext{
${ }^{3}$ Government of the People's Republic of Poland. (1978). World Heritage nomination dossier of the Historic Centre of Warsaw. p. 4.

${ }^{4}$ The Archive of the Warsaw Reconstruction Office, including documentation on both the post-war damage and the reconstruction project, was enlisted in the UNESCO Memory of the World Register in 2011.
} 
following extract from the 2018 Warsaw Recommendation can be read as if it were directly inspired by the efforts in those years:

Building resilience is essential to address destruction and disasters. In reconstructing heritage following an armed conflict or a disaster, it is critical to reduce existing structural and social vulnerabilities, including by building back better, and to improve quality of life, while retaining cultural values as much as possible.

The Baroque city centre of Dresden was reduced to ruins in February 1945, by the carpet bombing raids of World War II. Soon after the war, some of Dresden's historic buildings were to be reconstructed, such as the Zwinger Palace and Semper Opera House, with support of the Soviet Union as was the case of Warsaw. However, a prominent destructed landmark church of the old city of Dresden, the Frauenkirche, was left for half a century in a form of scorched ruins, partly as a memorial against war and partly due to the strict prohibition against activities for religious faith during the communist regime. Built in the middle of the eighteenth century as a Lutheran church, the Frauenkirche with its magnificent posture had been a loved and respected monument for the citizens of Dresden. The people compiled and conserved the rubbles preciously and took record, which eventually became useful when, after the fall of the Berlin Wall and reunification of Germany, a civil movement developed in order to reconstruct the Frauenkirche. The project realistically started in 1994, where new information technology was introduced, in order to simulate the falling path of each remaining fragment of stone, so that their original positions could be calculated and identified like a puzzle. The project was affected by flooding of the Elbe River in 2002, but the work continued to be diligently implemented by the German people with no delay. The reconstructed Frauenkirche, using as much of the original remnants as possible, finally reappeared with its dome in the skyline of Dresden in 2004. 60 years after destruction, it was reconsecrated in October 2005 with festive services, which became an emotional moment for the people.

In the case of the Old Bridge at Mostar (Bosnia and Herzegovina), a historic town that developed under the Ottoman Empire in the fifteenth and sixteenth centuries, it was destructed between 1992 and 1995 by acts of war in the Balkans. Since 1998, the Old Bridge underwent a reconstruction project under the auspices of UNESCO and the World Bank and was opened to the public in the summer of 2004, after 4 years of work. The Old Bridge Area of the Old City of Mostar was inscribed on the World Heritage List in 2005, and in the Statement of Outstanding Universal Value of the World Heritage property, the Bosnian authorities underline that "the reconstruction of the Old Bridge was based on thorough and detailed, multi-facetted analysis, relying on high quality documentation. The authenticity of form, use of authentic materials and techniques are fully recognizable while the reconstruction has not been hidden at all".

An interesting document on authenticity of the reconstructed bridge of Mostar is the ICOMOS Evaluation on the World Heritage nomination of this site:

On the basis of the test of authenticity, as defined in paragraph 24.b.i of the Operational Guidelines for the Implementation of the World Heritage Convention, there must be 
considerable reservations about the authenticity of Mostar (...). The Old Bridge has been rebuilt as a copy, using mainly new material, though with the integration of some of the historic material especially on the surface. The proportion of reconstructed buildings is very high, and much new material has also been used. (...) However the new (2005) Operational Guidelines gives a more detailed approach on this field, offering a series of "qualities" for testing authenticity. In this light, the result of a test of authenticity is rather more positive.

It compares the question of authenticity in light of the variant principles in the old (until 2002) and new (from 2005) versions of the Operational Guidelines, where the approach to authenticity justification broadens after discussions in the Nara Document. ICOMOS, against the former, expresses "considerable reservations" and, against the latter, becomes "rather more positive".

ICOMOS also stated in the same evaluation document that "it must be stressed that this reconstruction of fabric should be seen as being in the background compared with restoration of the intangible dimensions of this property, which are certainly the main issue concerning the Outstanding Universal Value of this site". The intangible dimension given by the Bosnian authorities as justification of World Heritage criteria (vi) was the discourse on the bridge as symbol of reconciliation and strengthening of coexistence of communities from diverse cultural, ethnic and religious backgrounds.

In Japan, in Okinawa, we can see today a prominent example of a reconstructed cultural heritage, namely, the Shuri Castle. First built in the fourteenth century by the Ryukyu Dynasty, it was a living castle until late nineteenth century and was listed as a national treasure before World War II. However, entirely devastated to the ground by heavy naval gunfire during World War II in 1945, the tangible memory of this castle, together with an entire historic urban landscape of Shuri and most other parts of the city of Naha, was eradicated from earth.

A major part of the large-scale reconstruction work of the Shuri Castle complex took place in the early 1990s, following an extensive research and planning period in the 1980s. The reconstruction work of the complex still continues today. However, at first, during the post-war period of Okinawa, occupied by the USA, it had seemed like a hopeless dream to reconstruct the forementioned castle of the Ryukyu Kingdom, particularly while the former castle site was used as a campus of a new university. Then, Okinawa was reverted to Japan in 1972 after 27 years. The university campus was to relocate elsewhere for its own reasons. The idea of reconstructing the castle was then first conceived within the resilient minds of the local civil society, who lived through the war-torn period of Okinawa. They voiced their will through determined actions towards recovery of Okinawa's cultural significance and for the survival of identity within the future generations. After a number of unsuccessful attempts, eventually, political support and interests matched their initiative, towards commemoration of the 20th anniversary of the reversion of Okinawa to Japan in 1992.

Certainly, the research phase started from further excavation before any rebuilding and documentation including compilation of photographs and drawings in particular from earlier restorations. However, at first, no archives could be found on the interior of the castle in the eighteenth century, when it still served dynamically as 
the royal court, to which the project aimed at restituting the architecture of the main state hall of the castle. Historians and engineers of the reconstruction team then found two further important archival documents on the eighteenth- and nineteenthcentury restoration works of the castle. This allowed them to move forward, to take 3 whole years of drawing and designing based on documentation, colour analysis and structural experiments. Unlike stone, the original wooden material of the castle buildings, apart from some parts of the coral stone ramparts, was reduced to ashes in 1945 and had not remained. Even the identification of material, to be precise on the type of wood, was only possible thanks to the details in discovered archives.

In 2000, the land surface and scarce remains of the foundations of the original Shuri Castle became part of a serial World Heritage property of "Gusuku sites and related properties of the Kingdom of Ryukyu". Precisely speaking, the reconstructed monuments and ramparts are not included in the Outstanding Universal Value of the World Heritage nomination. However, in the eyes of the present day's community, it is the vividly reconstructed castle which illustrates the recovered memory of Okinawa. The reconstructed castle complex has become the symbol of the identity of the lost Kingdom of Ryukyu and evokes the beauty of the urban landscape of Shuri, which existed until 1945. Reconstruction of the Shuri Castle could take place at the right momentum, when the local elders, survived after the war, could link their memories of the original castle to its new form.

Having hence observed some of the prominent previous cases in discussing destruction, reconstruction, memory and future building, these cases cover a number of common facts and issues:

- A powerful decision-making is undertaken, with coherent responsibility to reconstruct.

- In order to support realistic implementation, including financial resources, political (and international) backup is present, in a way or another.

- Appropriate documentation is available and survey is undertaken.

- Doctrinal contestation can come before, during or after the reconstruction work, but coherent and collective intention overrides hesitation.

- In most cases, the needs and interests of the local people become the nucleus of the work, for the place to continue towards the future, in other words, to survive.

- The tangibly reconstructed heritage, after loss through intentional destruction, has become a sharing platform of common memory, symbolic of recovery and restitution of identity.

Those mentioned cases seem to have been unquestionably of "exceptional circumstances", as it were, for reconstruction.

Here, when we think about reconstruction in "exceptional circumstances" to be "for the future" (and present) as a form of "future-making", we cannot deny consideration on conjecture, minor or major it may be, which would in many cases become unavoidable to some extent. We also need to review what conjecture means. This also concerns the issue of "who wishes to remember what and how" and the importance of memory to a sense of place. In our days when accurate documentation of cultural heritage is possible thanks to technology and dedicated expertise, 
nevertheless, we cannot expect documentation to be perfect upon reconstructing a vast area of monuments from scratch. During armed conflict, in heavily bombed places such as the cases studied above, where countless lives of civilians are ruthlessly lost, local documentation could also be severely damaged or lost. We could also be reminded that photographic documentation until half a century ago were not as complete as today, and some reconstruction details such as the exact colour of roof tiles, non-distinguishable in monochrome photographs, would perhaps need to rely on the memory of survived elders whose opinions could vary.

Strong criticism against conjecture became the basis of cautiousness towards reconstruction of cultural heritage, since the nineteenth century in countries such as the UK or France. We may look into the large-scale restoration works of the French architect and engineer Eugène Viollet-le-Duc in those years. The works he undertook in Pierrefonds or Carcassonne, even Notre-Dame de Paris, included what we today call reconstruction based on conjecture. This is a longstanding point of criticism. However, Viollet-le-Duc did study the vast amount of documentation upon designing his restoration works, which made him struggle and hesitate between various layers of forms that the monuments may have taken in the course of history. He eventually and decisively chose to put on additions to the monuments, in view of bearing their future forms, for those monuments to live in the hearts of the future nation. In the field of cultural heritage conservation, there is no doubt that retention of authenticity is at the highest respect of any work. However, in the hearts of the future community, a "new form" may also be accepted. In order to persuade the large global public, the principles of cultural heritage conservation would need to justify and better advocate the cautious approach towards reconstruction and the denial of what is considered as conjecture. The present author seeks meaning and significance of intended memory-building processes. Some monuments, literally speaking of the Latin word monere, to remind, were intended as cultural heritage from the beginning, while other cultural heritage became heritage, targets of conservation, venerated by later people who attributed value to certain vestiges from the past. Future-making or even "history-making": since it is a continuous process which we are involved at present, shouldn't the restitution of a memory from the past, when symbolically lost, be constructively considered as memory "for" the future societies?

\section{Conclusion}

There are stronger attachments and significance to tangible heritage when we use it, live with it, and are moreover being associated in building it. If there could be a revival or transmission of the spirit of building a Buddha statue, through elaborate works of reconstruction, within the ownership of whoever lives with it, there must be a meaning. However, if we are too much concentrated on the visual aspects, with less consideration on the motivation and spirit of "by whom" and "for whom", for example, a strong identity recovery of the local and national community, there may 
be little point in physical reconstruction of a statue. It will be a mere replica, if made without crystallization of spontaneous power, including intention, emotion and participation, of the people associated with the place.

Any reconstruction of cultural heritage needs initiative and motivation of the local community, with open consultations with the local and national authorities, involving a large financial support. Clarification of the process of consensus building and decision-making is key to justification of reconstruction. As in the Warsaw Recommendation, "recovery and reconstruction should enable people to connect to their heritage, identity and history. (...) it is important to identify cultural rights and their holders (...) and to ensure their prior and informed consent to key decision".

If the Giant Buddha statues of Bamiyan are to be reconstructed in the future, it would be for the restitution of historic memory and identity. In the Statement of Outstanding Universal Value of the World Heritage property of the Cultural Landscape and Archaeological Remains of the Bamiyan Valley, concerning integrity of the site, the Afghan authorities mentions that "a major loss to the integrity of the site was the destruction of the large Buddha statues in 2001". This official statement illustrates the incompleteness of the cultural heritage property, indeed as in the Riga Charter, where a place is incomplete through damage or alteration. From what this paper observed and argued, Bamiyan is a place that seems rightly justifiable as of "exceptional circumstances". However, we must still continue to question and clarify "who wishes to remember what and how" and who are the main stakeholders to take responsibility in the decision-making on the future of the heritage place. At the same time, when it comes to "for whom", it is about thinking what is the value for the "concerned community" in terms of reconstructing their memory in a tangible form for the future. The answer to these question becomes crucial to resurrect or not the Giant Buddha statues of Bamiyan as an exceptional case for reconstruction and on the choice of the reconstruction method. Here, if there is too much focus on authenticity in terms of "how it used to be in the past", when it is unrealistic due to lack of documentation, loss of original material or clear memory, the unique motivation of reconstruction, in "exceptional circumstances" for the recovery of the present, may be weakened. History-making new elements shall be part of heritage, bridging the past and future.

Including the case of Bamiyan, if a cluster of "exceptional circumstances" and conformed reconstruction processes could be demonstrated in our contemporary world, it would become beneficial as best practice references and feed into up-todate principles, for present day's decomposed societies to be supported internationally. They must move on to rebuild and revitalize their livelihood and pride, through reconstruction of cultural heritage as their living environment at large.

The present author, in consideration of the exceptional acceptance of reconstructions, intends to emphasize the following arguments for the making of future. Significance of reconstruction is not only about rebuilding the monument in the materialistic sense but also to revitalize the living environment of the local community in their familiar context. This is to foresee the rehabilitation of social livelihood and restitution of self-esteem among the directly concerned community. On condition that reconstruction of an architectural or monumental space could materialize 
such envisaged situations, it should be acceptable as an appropriate conservation method and as a forward-looking future society management.

In order to strengthen this argument, the paper concludes its position in the assertive support towards identification of "exceptional circumstances" for reconstruction and that any action should need to grasp the appropriate momentum, before the place may lose hope of motivated communities towards regaining the sense of place of their cherished homelands.

\section{Bibliography}

\section{International Principles, Proceedings, Reports and Official Documents}

Asahi-Shinbun (Ed.). (2003). Recovering the Missing Treasures of Afghanistan and Iraq: An Urgent Appeal from Ikuo Hirayama, Tokyo.

First International Congress of Architects and Technicians of Historic Monuments. (1931). Athens Charter for the Restoration of Historic Monuments, Athens.

Government of Japan. (1999). World Heritage nomination dossier of the Gusuku Sites and Related Properties of the Kingdom of Ryukyu.

Government of the People's Republic of Poland. (1978). World Heritage nomination dossier of the Historic Centre of Warsaw.

ICOMOS. (1980). Evaluation on the World Heritage nomination of the Historic Centre of Warsaw.

ICOMOS. (2000). Evaluation on the World Heritage nomination of the Gusuku Sites and Related Properties of the Kingdom of Ryukyu.

ICOMOS. (2003). Evaluation on the World Heritage nomination of the Cultural Landscape and Archaeological Remains of the Bamiyan Valley.

ICOMOS. (2005). Evaluation on the World Heritage nomination of the Old Bridge Area of the Old City of Mostar.

International Conference on Reconstruction: "The Challenges of World Heritage Recovery”. (2018). Warsaw Recommendation on Recovery and Reconstruction of Cultural Heritage, Warsaw.

Nara Conference on Authenticity in Relation to the World Heritage Convention. (1994). Nara Document on Authenticity, Nara.

National Research Institute for Cultural Property, Japan (Ed.). (2005). Preserving Bamiyan: Proceedings of the International Symposium "Protecting the World Heritage Site of Bamiyan", 21 December 2004. Tokyo: Akashi-Shoten.

Regional Conference on Authenticity and Historic Reconstruction in Relationship with Cultural Heritage. (2000). Riga Charter on Authenticity and Historic Reconstruction in Relationship with Cultural Heritage, Riga.

Second International Congress of Architects and Technicians of Historic Monuments. (1964). International Charter for the Conservation and Restoration of Monuments and Sites, Venice.

Transitional Islamic State of Afghanistan. (2003). World Heritage nomination dossier of the Cultural Landscape and Archaeological Remains of the Bamiyan Valley.

UNESCO. (2018). Background Document on the Challenges of World Heritage Recovery - The Reflection on Reconstruction within World Heritage Properties as a Complex Multi-disciplinary Process, Paris.

UNESCO. (2019). Operational Guidelines for the Implementation of the World Heritage Convention. rev. edn. Paris. 


\section{Literature}

Brandi, C. (1977). Teoria del Restauro, English Edition: Brandi, C. (2005). Theory of Restoration, translated by Rockwell, C., edited by Istituto Centrale per il Restauro. Firenze: Nardini Editore.

Choay, F. (1992). L'Allégorie du patrimoine. Paris: Seuil.

Choay, F. (2009). Le patrimoine en questions. Paris: Seuil.

Jokilehto, J. (2013). Reconstruction in the World Heritage Context. Rome: European Association for Architectural Education.

Murphy, K. (2000). Memory and modernity: Viollet-le-Duc at Vézelay. University Park: Pennsylvania State University Press.

Stig Sørensen, M. L., \& Viejo-Rose, D. (Eds.). (2015). War and Cultural Heritage: Biographies of Place. Cambridge: Cambridge University Press.

\section{Articles}

Shimada, T. (2006). Dresden's Frauenkirche reconstructed after 60 years. Goken News, 15, 6-8 Nagoya: Aichi University.

The Guardian. (2016). Story of Cities: \#28: how postwar Warsaw was rebuilt using 18th century paintings. [Online]. Available at: https://www.theguardian.com/cities/2016/apr/22/story-citieswarsaw-rebuilt-18th-century-paintings/. Accessed 30 Sept 2017.

UNESCO World Heritage Centre News and Events. (2015). Reconstruction of Timbuktu mausoleums nears completion. [Online]. Available at: http://whc.unesco.org/en/news/1307/. Accessed 20 Dec 2017.

The opinions expressed in this chapter are those of the author(s) and do not necessarily reflect the views of the UNESCO, its Board of Directors, or the countries they represent.

Open Access This chapter is licensed under the terms of the Creative Commons AttributionShareAlike 3.0 IGO License (https://creativecommons.org/licenses/by-sa/3.0/igo/), which permits use, sharing, adaptation, distribution, and reproduction in any medium or format, as long as you give appropriate credit to UNESCO, provide a link to the Creative Commons licence and indicate if changes were made. If you remix, transform, or build upon this chapter or a part thereof, you must distribute your contributions under the same licence as the original. This publication is also available at the UNESCO Open Access Repository: https://unesdoc.unesco.org/

The designations employed and the presentation of material throughout this publication do not imply the expression of any opinion whatsoever on the part of UNESCO concerning the legal status of any country, territory, city or area or of its authorities, or the delimitation of its frontiers or boundaries.

The authors are responsible for the choice and the presentation of the facts contained in this chapter and for the opinions expressed therein, which are not necessarily those of UNESCO and do not commit the Organization.

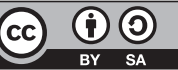

